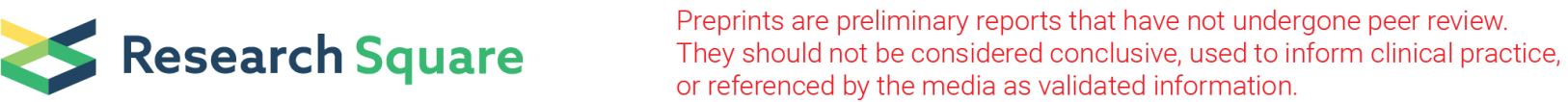

\section{Characterization of the Bacterial Microbiome of Rhipicephalus (Boophilus) Microplus Collected From Pecari Tajacu "sajino" Madre De Dios, Peru}

JESUS ROJAS-JAIMES ( $\sim$ jesus.rojas.jaimes@gmail.com )

Facultad de Ciencias de la Salud, Universidad Privada del Norte, Lima-Peru

David Lindo Seminario

DATAOMICS

German Correa Núñez

Universidad Amazonica de Madre de Dios

Benoit Diringer

Incabiotec

\section{Research}

Keywords: Metagenomics, Riphicephalus microplus, Pecari tajacu, microbiome, bacteria

Posted Date: October 27th, 2020

DOI: https://doi.org/10.21203/rs.3.rs-96288/v1

License: (c) (i) This work is licensed under a Creative Commons Attribution 4.0 International License. Read Full License 


\section{Abstract}

Background: Ticks are arthropods that can host and transmit pathogens to wild animals, domestic animals, and even humans.

Methods: The bacterial microbiome of adult (males and females) and nymph Rhipicephalus microplus ticks collected from a collared peccary, Pecari tajacu, captured in the rural area of Botijón Village in the Amazon region of Madre de Dios, Peru, was evaluated using metagenomics.

Results: The Chao1 and Shannon-Weaver analyses indicated greater bacterial richness and diversity in female ticks (GARH; 375-4.15) and nymph ticks (GARN; 332-4.75) compared to that in male ticks (GARM; 215-3.20). Taxonomic analyses identified 185 operational taxonomic units representing 147 bacterial genera. Of the 25 most prevalent genera, Salmonella (17.5\%) and Vibrio (15.0\%) showed the highest relative abundance followed by several other potentially pathogenic genera, such as Paracoccus (7.8\%), Staphylococcus (6.8\%), Pseudomonas (6.6\%), Corynebacterium (5.0\%), Cloacibacterium (3.6\%), and Acinetobacter (2.5\%). In total, $19.7 \%$ of the detected genera are shared by GARH, GARM, and GARN, and they can be considered as the core microbiome of $R$. microplus.

Conclusions: To the best of our knowledge, this study is the first to characterize the microbiome of ticks collected from P. tajacu and to report the presence of Salmonella and Vibrio in R. microplus. The pathogenic potential and the role of these bacteria in the physiology of $R$. microplus should be further investigated due to the possible implications on public health and animal health in populations neighboring the habitat of $P$. tajacu.

\section{Background}

Ticks are arthropods that can host a range of pathogens of other organisms and are one of the main vectors for metaxene diseases [1]. Babesia sp. and Rickettsia sp. are pathogens frequently transmitted by ticks, whose detection and identification have been facilitated by molecular methods, particularly by the emergence of next-generation sequencing (NGS) techniques [2, 3]. NGS techniques allow for (i) the precise characterization of the composition of complex microbiomes independent of the traditional culture techniques, (ii) the identification of pathogens, opportunists, probiotics, or commensals for the arthropod and/or host, and (iii) the calculation and comparison of the diversity and richness of microbiomes [4]. Although commensal and symbiotic bacteria have been identified by metagenomic studies in ticks $[4,5]$, these studies have focused on the microbiome with pathogenic potential from the veterinary and human perspective [6]. The microbiome biology in ticks still remains generally unexplored and neglected, and whether the microbiome has a neutral, harmful, or beneficial effect on the arthropod with regard to nutritional processes, adaptation, development, reproduction, or defense in adverse environments needs to be determined [6]. Furthermore, previous studies on Ixodes pavlovskyi have described Rickettsia, Anaplasma, Ehrlichia, and Borrelia burgdorferi as well as their impact on the vector and susceptible hosts $[6,7]$. Another study on Dermacentor occidentalis has identified an emerging 
pathogenic bacterium in humans called Rickettsia philipii as well as two new bunyaviruses [8]. The microbiome of Rhipicephalus (Boophilus) microplus has been characterized in cattle by pyrosequencing techniques [9], while the pathogens Anaplasma, Bartonella, Borrelia, Ehrlichia, Francisella, and Rickettsia have been identified in ticks of the genera Amblyomma sp., Ixodes sp., and Haemaphysalis sp. [10]. Metagenomics has also been used to identify other infectious agents in Rhipicephalus sp., such as viruses, particularly nairoviruses that cause important diseases in humans [11].

This study aims to analyze the bacterial microbiome in $R$. microplus collected from wild Pecari tajacu using metagenomics.

\section{Methods}

\section{Ethical aspects}

This study was approved by the Oficina de Salud Pública y Medio Ambiente del Consejo Regional de Madre de Dios (Office of Public Health and Environment of the Regional Council Madre de Dios), Peru. Laboratory procedures for bacterial identification were conducted in accordance with the international guidelines for the use of animals in research and the standards of the Comite de Cuidado y Uso de Animales del Área de Investigación en Salud de la Junta del Consejo Regional de Madre de Dios (Animal Care and Use Committee of the Health Research Area of the Madre de Dios Regional Council Board).

\section{Geographic location}

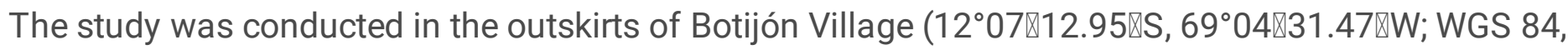
267 m.a.s.I.), Tambopata province, Madre de Dios region, Peru (Figure 1). The collection site corresponds to a forest area where hunting of wild animals is allowed. The average annual rainfall in the study area is $1,600 \mathrm{~mm}^{3}$, and the average annual temperature is $25^{\circ} \mathrm{C}$. The area is in the tropical wet forest zone. During sample collection, the weather was hot and humid.

\section{Sample collection}

A wild male of $P$. tajacu (sajino) was captured in Botijón Village in June 2012. The ticks from its abdominal region were collected $3 \mathrm{~h}$ after its sacrifice using forceps and were individually placed in $2 \mathrm{ml}$ cryovials containing $96 \%$ ethyl alcohol. Cryovials were labeled with an identification code for the sampling site and the animal from which the sample was collected. Five male ticks, five female ticks, and two nymph ticks were identified.

\section{Taxonomic classification}

Ticks were identified using taxonomic keys [12] at the Laboratorio de Entomología del Instituto Nacional de Salud del Perú en Lima (Entomology Laboratory of the National Institute of Health of Peru in Lima).

\section{DNA extraction}


Total DNA extraction from ticks was performed using Gentra Puregene Tissue kits (QIAGEN®, HaldenGermany) according to the manufacturer's instructions [13] from pools for each tick sex and stage, i.e., GARH (females), GARM (males), and GARN (nymphs) pools.

\section{Metagenomics}

To study the bacterial diversity and richness in the microbiota from Rhipicephalus microplus, the presence and quality of the extracted DNA was verified by PCR amplification of the 16S rRNA gene [14] using the universal primers 27F (5'- AGAGTTTAGTCMTGGCTCAG-3 ') and 1492R (5'-

GGYTACCTTGTTACGACTT-3') that generate a product of about 1500 base pairs (bp). All reactions were performed in $25 \mu \mathrm{l}$ (total volume) mixtures containing $2.5 \mu \mathrm{l}$ 10X buffer, $2.5 \mu \mathrm{l} 25 \mathrm{mM} \mathrm{MgCl}_{2}, 0.6 \mu \mathrm{l} 10$ $\mathrm{mM}$ dNTPs, and $2 \mathrm{U}$ of Taq DNA polymerase (Thermo Scientific). The PCR conditions were as follows: initial denaturation at $95^{\circ} \mathrm{C}$ for 5 min followed by 35 cycles of denaturation at $95^{\circ} \mathrm{C}$ for $30 \mathrm{~s}$, hybridization at $55^{\circ} \mathrm{C}$ for $45 \mathrm{~s}$, elongation at $72{ }^{\circ} \mathrm{C}$ for $1 \mathrm{~min}$, and a final elongation at $72{ }^{\circ} \mathrm{C}$ for $10 \mathrm{~min}$. The PCR products were visualized by electrophoresis on a $1.5 \%$ agarose gel.

Total DNA extractions were analyzed by spectrophotometry (Nanodrop ${ }^{\mathrm{TM}}$ Eppendorf), and the samples with sufficient quality and quantity were shipped to MR DNA (Shallowater, TX, USA) and sequenced on the $\mathrm{PGM}^{\mathrm{TM}}$ platform (Ion Personal Genome Machine System, Thermo Fisher Scientific). Metagenomic analysis was performed on the PCR amplification products of the V4 hypervariable region of the $16 \mathrm{~S}$ rRNA gene using the 515F/806R primers [15].

\section{Analysis and processing of metagenomic data}

The sequences generated by lon Torrent were analyzed with QIIME v1.9.1 [15], where the initial sequences were processed based on filtering of barcodes $\leq 6 \mathrm{bp}$, Q25 quality scores, $150 \mathrm{bp}$ sequence length, and chimera detection using usearch61 [16,17]. High-quality sequences were assigned to operational taxonomic units (OTUs) with a $97 \%$ identity cutoff for bacteria. The final OTUs were classified taxonomically using the High Quality Ribosomal RNA Databases "SILVA" v132 database (https://www.arb-silva.de/). Likewise, unrepresentative OTUs $\leq 0.005 \%$ were filtered during analysis [18].

Lastly, the final OTUs were processed to analyze the Shannon-Weaver (SW) alpha diversity index, Chao1 richness index, beta diversity (venn and heatmap), and taxonomic abundance (barplot) of the microbial communities using the phyloseq and ampvis packages with the statistical program RStudio version 3.2.3. $[16,19,20]$. Sequences shorter than 250 bp were removed. The obtained OTUs were then taxonomically classified using BLASTn and compared with a curated database derived from Greengenes, RPDII, and NCBI (www.ncbi.nlm.nih.gov [21], http://rdp.cme.msu.edu [15]). The sequences were registered in Metagenomics Analysis Server "MG-RAST" ID: mgp95793; available at https://www.mgrast.org/linkin.cgi?project=mgp95793.

\section{Results}




\section{Ticks collected from $P$. tajacu}

Taxonomic identification indicated that all the collected ticks belong to R. microp/us [12].

\section{Statistical values and diversity in the $R$. microplus microbiome}

Microbiome analysis using the 16s-515F/16s-806R primers and amplicon sequencing on lon Torrent $\mathrm{PGM}^{\mathrm{TM}}$ generated a total of 117,192 raw reads (39,604 average) from the three analyzed samples (Table 1). After rigorous data curation, 55,805 high-quality sequences were retained with an average of 20,462 sequences per sample and an average length of $150 \mathrm{bp}$. The maximum number of filtered sequences $(26,549)$ was obtained from the female tick sample, which exceeded those found in male and nymph samples by $164.7 \%$ and $204.8 \%$, respectively. These sequences were assigned to 1,075 total unique sequences corresponding to 185 abundant $(<0.005 \%)$ OTUs based on a $>97 \%$ identity cutoff for bacterial $16 S$ rRNA genes. At the individual sample level, the microbiome from nymphs surpassed that from females and males $(221,195$, and 148 OTUs, respectively). Those OTUs were mainly identified as prokaryotes $(99.89 \%)$ and to a lesser extent as unknown sequences $(0.11 \%)$. At the taxonomic level, a total of 147 genera distributed in 99 families, 59 orders, 30 classes, and 12 phyla were detected.

The SW index reflects the specific diversity of each sample, whose value increases as the number of different OTUs increases. In this study, the microbiome obtained from nymph tick samples showed a higher SW index than the female and male microbiomes. On the other hand, Chao1, the index that evaluates specific richness, showed that the number of expected OTUs decreased from 375 in GARH to 332 in GARN and 215 in GARM after the standardization of the sample size to 14,000 sequences.

Statistical analyses of variance of the SW and Chao1 indexes in the GARH, GARM, and GARN samples showed significant differences $(P<0.01)$.

Table 1. Statistical summary of the microbiota from Rhipicephalus microplus. 


\begin{tabular}{|c|c|c|c|}
\hline Sample size & GARH & GARM & GARN \\
\hline Number of total sequences & 56,059 & 32,524 & 28,609 \\
\hline Number of filtered sequences & 29,084 & 18,103 & 14,200 \\
\hline Number of sequences assigned to OTUs & 26,549 & 14,045 & 14,145 \\
\hline Number of OTUs & 221 & 148 & 195 \\
\hline Phylum & 10 & 6 & 9 \\
\hline Class & 19 & 15 & 15 \\
\hline Order & 43 & 29 & 34 \\
\hline Family & 62 & 41 & 55 \\
\hline Gender & 87 & 57 & 82 \\
\hline Richness and diversity indexes & & & \\
\hline Chao1 & $375^{\star}$ & $215^{\star}$ & $332 *$ \\
\hline Shannon-Weaver & $4.15^{\star}$ & $3.20 *$ & $4.75^{\star}$ \\
\hline
\end{tabular}

*Significant differences $(P<0.01)$

\section{Composition of the core and shared and individual microbiome from $R$. microplus}

The comparative analysis of the composition of the microbiota from GARH, GARM, and GARN revealed that $19.7 \%$ out of the 147 genera found in $R$. microplus were common to the three groups. This shared community is considered as the core microbiota (Table 2). The percentages showed a decreasing 
proportionality in GARH, GARN, and GARM in relation to the non-shared bacterial genera. A higher percentage of shared microbiota was observed between GARH and GARN (9.5\%) compared to that between GARM and GARH (3.4\%) and between GARM and GARN (1.4\%).

Table 2. Composition of the core microbiome according to $R$. microp/us sex and stage.

\begin{tabular}{|c|c|c|}
\hline Codes & Total & Genera \\
\hline $\begin{array}{l}\text { GARH } \\
\text { GARM } \\
\text { GARN }\end{array}$ & $\begin{array}{l}29 \\
(19.7 \%)\end{array}$ & $\begin{array}{l}\text { Streptococcus Brevundimonas Micrococcus Pseudomonas Corynebacterium } \\
\text { Acinetobacter Staphylococcus Brachybacterium Ornithinimicrobium } \\
\text { Lysobacter Brevibacillus Stenotrophomonas Other Bacillus Citrobacter } \\
\text { Pluralibacter Janibacter Sphingomonas Salmonella Rothia Tepidimonas } \\
\text { uncultured bacterium Nocardioides Paracoccus Aeromonas Vibrio } \\
\text { Enterobacter Cloacibacterium Anoxybacillus }\end{array}$ \\
\hline $\begin{array}{l}\text { GARH } \\
\text { GARM }\end{array}$ & $\begin{array}{l}5 \\
(3.4 \%)\end{array}$ & Trabulsiella Schlegelella Anaerococcus Actinomyces Neisseria \\
\hline $\begin{array}{l}\text { GARH } \\
\text { GARN }\end{array}$ & $\begin{array}{l}14 \\
(9.5 \%)\end{array}$ & $\begin{array}{l}\text { Blastococcus Sphingobacterium uncultured Comamonas Halomonas Dietzia } \\
\text { Cupriavidus Tetrasphaera Granulicatella Thermus Deinococcus Kocuria } \\
\text { Unassigned Rheinheimera }\end{array}$ \\
\hline $\begin{array}{l}\text { GARM } \\
\text { GARN }\end{array}$ & $\begin{array}{l}2 \\
(1.4 \%)\end{array}$ & Brachymonas Lactococcus \\
\hline GARH & $\begin{array}{l}39 \\
(26.5 \%)\end{array}$ & $\begin{array}{l}\text { Phreatobacter Lawsonella Ruegeria Alteromonas Saccharopolyspora } \\
\text { Bergeyella Enhydrobacter Prevotella Pseudorhodoferax Solobacterium } \\
\text { Hydrogenobacter Morganella Gibbsiella Salinimicrobium Haematobacter } \\
\text { Chryseobacterium uncultured Gemmatimonadetes bacterium Paenibacillus } \\
\text { Gemella Cellvibrio Aquabacterium Abiotrophia Thiopseudomonas } \\
\text { Craurococcus Peptoniphilus Myroides Bacteroides Shewanella } \\
\text { Chroococcidiopsis Macrococcus Ensifer Gordonia Plesiomonas Salinicoccus } \\
\text { Alishewanella Porphyromonas Fructobacillus Pantoea Lactobacillus }\end{array}$ \\
\hline GARM & $\begin{array}{l}21 \\
(14.3 \%)\end{array}$ & $\begin{array}{l}\text { Vulcaniibacterium Roseomonas Eikenella Enteractinococcus Mycobacterium } \\
\text { Enterococcus llumatobacter Propioniciclava Hydrogenophilus Rubrobacter } \\
\text { Peredibacter Georgenia Veillonella Thauera Chryseomicrobium } \\
\text { Gemmatimonas Propionibacterium Diaphorobacter Cnuella Asticcacaulis } \\
\text { Domibacillus }\end{array}$ \\
\hline GARN & $\begin{array}{l}37 \\
(25.2 \%)\end{array}$ & $\begin{array}{l}\text { Ochrobactrum Atopostipes Marinilactibacillus Alkalibacterium } \\
\text { Paramesorhizobium Psychrobacter Ralstonia Sphingorhabdus } \\
\text { Quadrisphaera Sphingobium Ottowia Exiguobacterium Brevibacterium } \\
\text { Haemophilus Aerococcus Bradyrhizobium Luteimonas Flavobacterium } \\
\text { Nannocystis Ruminococcus Novosphingobium Aeromicrobium } \\
\text { Rubellimicrobium Acidovorax Pleomorphomonas Erythrobacter } \\
\text { Sandaracinus Bordetella Serinicoccus Weissella Gardnerella Candidatus } \\
\text { Alysiosphaera Klebsiella Leptotrichia Actinobacillus Isoptericola } \\
\text { Atopococcus }\end{array}$ \\
\hline
\end{tabular}

\section{Microbiota according to $R$. microplus sex and stage}


Regarding the abundance of bacterial genera in R. microplus, Salmonella was the most abundant genus in GARM, while Vibrio was the most abundant genus in GARH and GARN, and Paracoccus was the second most abundant genus in GARH. On average, these were the most abundant genera in $R$. microplus, $17.5 \%, 15 \%$, and $7.8 \%$, respectively (Figure 2 ).

\section{Discussion}

The richness and diversity indexes revealed that the microbiota present in GARH and GARN exhibit greater bacterial genera diversity and richness than the microbiota in GARM. This is in agreement with previous studies on $R$. microp/us that were collected from cattle [9]. Previous studies in male and female ticks of Ixodes ovatus, I. persulcatus, and Amblyomma variegatum have shown differentiated microbiome profiles both at the taxonomic and functional levels between sexes of the same tick species [22].

A metagenomic study showed that the microbiome profile in ticks is related to metabolic processes and that their resilience and adaptability to the environment is related to their sex [22]. In addition, geographical location, temperature, humidity, species, sex, anatomical location, and type of food have been shown to affect the microbiome of ticks [23-28]. In our study, although ticks were of the same species and were collected from the same host, significant differences were found in bacterial diversity and richness related to the sex and developmental stage of ticks.

Among the 147 different genera identified, the core microbiome that included the majority of the most prevalent genera stood out. Several of the identified genera within the core microbiome are known to be human pathogens (i.e., Salmonella, Vibrio, Paracoccus, Staphylococcus, Pseudomonas, Corynebacterium, Cloacibacterium, and Acinetobacter). In addition, a greater bacterial microbiome was shared between nymph and female ticks [14 (9.5\%)] compared to that shared between male and female ticks [5 (3.4\%)]. We suggest that these differences have a behavioral origin. Thus, female and nymph ticks are more prone to remain on the same host, whose microbiota impact on the tick gut microbiome, while male ticks frequently change hosts [22]. This hypothesis is supported by studies on other genera that reported higher relative abundance and alpha diversity in female ticks than in male ticks [22].

The most prevalent genus among the three groups of ticks was identified as Salmonella, whose members cause gastrointestinal tract infection and dysentery and can lead to serious clinical conditions, especially in children [29]. The genus Vibrio, the second in abundance (15.6\%), represents a finding of great interest as, to the best of our knowledge, this is the first study showing its presence in $R$. microplus. The genus Vibrio is a common commensal of aquatic arthropods and has a remarkable capacity for adaptation to the environment [30,31]. Its presence evinces the adaptation of this genus to the gastrointestinal system of $R$. microplus, which inhabits a jungle ecosystem. Many Vibrio are opportunistic pathogens of both arthropods and humans. Therefore, studying the virulence of the identified species is essential [30-32]. Paracoccus, the third most abundant genus (6.97\%), is a coccobacillary bacterium that is typically 
present in a wide range of ecosystems [33]. Staphylococcus, with a prevalence of $6.63 \%$, is mainly related to infections in soft tissues and has been previously reported in the intestines of $R$. microplus and with a high prevalence in female Amblyomma variegatum [9, 22]. Pseudomonas showed an abundance of $5.87 \%$ in $R$. microplus. In previous studies, the presence of this bacterial genus in $R$. microplus and in male Amblyomma variegatum with a high prevalence has been reported $[9,22]$. Pseudomonas has been suggested to be involved in the infection of soft tissues, including the tissues of the respiratory system $[34,35]$. The presence of Corynebacterium, with an abundance of $5.87 \%$, is important because some Corynebacterium species produce the diphtheria toxin or can cause osteomyelitis [36]. In addition, this genus has been previously identified in eggs and male adults of $R$. microplus [9]. Cloacibacterium, with a prevalence of $2.93 \%$ in $R$. microplus, are gram-negative bacteria that proliferate in aqueous environments with high content of organic matter [37]. Acinetobacter, with an abundance of $2.53 \%$, has been reported in a metagenomic study in I. persulcatus, I. pavlovskyi, and Dermacentor reticulatus [38]. Sphingomonas, the ninth most abundant genus (2.47\%), includes non-fermenting and strictly aerobic gram-negative bacteria. Some species, such as $S$. paucimobilis and $S$. wittichii, can cause infections in immunocompromised patients $[39,40]$.

In contrast to the bacterial microbiome relevant to human health identified in our study, a previous study on bacterial diversity in R. microplus collected from cattle identified Ehrlichia sp., Coxiella sp., and Bartonella sp. [41]. This indicates that the bacterial microbiome would also depend on the host parasitized by the ticks. Some bacteria, such as Leptospira interrogans, Mycobacterium, Salmonella, Clostridium, and Pasteurella, and tick genera, such as Haemaphysalis, Dermacentor, and Amblyoma, have been identified in the genus Pecari [42-44]. In our case, $R$. microplus, a tick that mainly parasitizes cattle [45], was found in P. tajacu (sajino). P. tajacu was possibly tick infected due to the proximity of Botijón Village, where livestock farming is practiced. This highlights that ticks can infect cattle, P. tajacu, and humans, with the potential risks of pathogen transmission that this implies.

Regarding the role of bacteria in ticks, note that nonpathogenic microorganisms present in ticks could cause infections in humans and other animals. For example, ecological studies have shown that Rickettsia, Francisella, and Coxiella, which are considered vertebrate pathogens, can change their pathogenic role and have a mutualistic and symbiotic relationship with ticks [1]. Therefore, studying the interaction between the bacterial microbiota and ticks is of utmost importance for the control of pathogens and the development of the arthropod [1]. Coxiella sp. infects at least two-third of the ticks and is important for the survival of Amblyomma americanum and Rhipicephalus sp. [46, 47]. Nonetheless, it has not been found in our study. Coxiella sp. and Francisella sp. are linked to the synthesis of vitamins necessary for the survival of ticks [48-50]. Likewise, other symbiotic bacteria, such as Francisella, Rickettsia, and Rickettsiella, have been reported [46], with Rickettsia sp. and Coxiella sp. having become strict endosymbionts [1].

\section{Conclusions}


In this study, we found a high bacterial diversity in female, male, and nymph $R$. microplus collected from $P$. tajacu. The greatest bacterial diversity and richness was found in females and nymph ticks compared to male ticks. The most frequent bacterial genera were Salmonella, Vibrio, and Paracoccus. This is the first bacterial metagenomic study performed in R. microplus collected from P. tajacu in the Peruvian jungle, and the presence of Vibrio is highlighted. This study lays the foundations for future studies on the importance of the role of the identified bacteria on arthropods and animal and human health.

\section{Abbreviations}

GARH: Female tick; GARM: Male tick; GARN: Nymph tick; m.a.s.l.: Meters above sea level; PCR:

Polymerase chain reaction; SW: Shannon-Weaver; OTU: Operational taxonomic units; PGM: Ion Personal Genome Machine System; NGS: next-generation sequencing; rRNA: Ribosomal RNA; WGS: World Geodetic System; SW: Shannon-Weaver; NCBI: National Center for Biotechnology Information; pb: Base pairs

\section{Declarations}

\section{Acknowledgements}

Marcelo B. Labruna of the Departamento de Medicina Veterinaria Preventiva y Salud Animal Facultad de Medicina Veterinaria y Zootecnia of the Universidad de São Paulo for his advice and review of this article; Dr. Eric Mialhe for funding the molecular studies; Cesar Chanta for his support in the laboratory procedures in Incabiotec SAC.

\section{Authors' contributions}

JRJ designed, performed the field work, and wrote and approved the final version of the article. GCN performed the field work and wrote and approved the final version of the article. DLS performed the analysis and bioinformatics study and approved the final version of the article. BD designed the molecular study and wrote and approved the final version of the article.

\section{Funding}

Not applicable

\section{Availability of data and materials}

Not applicable

\section{Ethical approval and consent to participate}

Not applicable

\section{Consent for publication}


Not applicable

\section{Competing interests}

The authors declare that they have no competing interest.

\section{References}

1. Bonnet SI, Binetruy F, Hernández-Jarguín AM, Duron O. The Tick Microbiome: Why Non-pathogenic Microorganisms Matter in Tick Biology and Pathogen Transmission. Front. Cell. Infect. Microbiol. 2017;7:236. doi: 10.3389/fcimb.2017.00236

2. Burgdorfer $W$, Hayes $S$, Mavros A. Non-pathogenic rickettsiae in Dermacentor andersoni: a limiting factor for the distribution of Rickettsia rickettsii. In: Burgdorfer AA, Anacker RL, editors. Rickettsia and Rickettsial Disease. New York: Academic; 1981. p. 585-594.

3. Chauvin A, Moreau E, Bonnet S, Plantard O, Malandrin L. Babesia and its hosts: adaptation to longlasting interactions as a way to achieve efficient transmission. Vet. Res. 2009;40:37. doi:10.1051/vetres/2009020.

4. Ravi A, Ereqat S, Al-Jawabreh A, Abdeen Z, Abu Shamma O, Hall H, et al. Metagenomic profiling of ticks: Identification of novel rickettsial genomes and detection of tick-borne canine parvovirus. PLoS Negl Trop Dis. 2019;13(1):1-19.

5. Greay TL, Gofton AW, Paparini A, Ryan UM, Oskam CL, Irwin PJ. Recent insights into the tick microbiome gained through next-generation sequencing. Parasites and Vectors. 2018;11(1):1-14.

6. Rar V, Livanova N, Tkachev S, Kaverina G, Tikunov A, Sabitova Y, et al. Detection and genetic characterization of a wide range of infectious agents in Ixodes pavlovskyi ticks in Western Siberia, Russia. Parasites and Vectors. 2017;10(1):1-24.

7. Filippova NA. Ixodid ticks of the subfamily Ixodinae. Fauna of the USSR. Arachnida. Leningrad: Publishing House Nauka; 1977. (In Russian).

8. Bouquet J, Melgar M, Swei A, Delwart E, Lane RS, Chiu CY. Metagenomic-based Surveillance of Pacific Coast tick Dermacentor occidentalis Identifies Two Novel Bunyaviruses and an Emerging Human Ricksettsial Pathogen. Sci Rep [Internet]. 2017;7(1):1-10. doi:http://dx.doi.org/10.1038/s41598-017-12047-6.

9. Andreotti R, De León AAP, Dowd SE, Guerrero FD, Bendele KG, Scoles GA. Assessment of bacterial diversity in the cattle tick Rhipicephalus (Boophilus) microplus through tag-encoded pyrosequencing. BMC Microbiol. 2011;11 (6):1-11

10. Nakao R, Abe T, Nijhof AM, Yamamoto S, Jongejan F, lkemura T, et al. A novel approach, based on BLSOMs (Batch Learning Self-Organizing Maps), to the microbiome analysis of ticks. ISME J [Internet]. 2013;7(5):1003-15. doi:http://dx.doi.org/10.1038/ismej.2012.171

11. Xia H, Hu C, Zhang D, Tang S, Zhang Z, Kou Z, et al. Metagenomic profile of the viral communities in rhipicephalus spp. ticks from Yunnan, China. PLoS One [Internet]. 2015;10(3):1-16. 
doi:http://dx.doi.org/10.1371/journal.pone.0121609

12. Barros-Battesti D, Arzua M, Bechara H. Carrapato de Importância Medico-Veterinaria da Região Neotropical: Um Guia llustrado para Identificação de Espécies [Ticks of Medical-Veterinary Importance in the Neotropical Region: An Illustrated Guide for Species Identification]. 10ma edição. Sao Paulo: Butantan Publicação; 2006. p. 223.

13. QIAGEN. Gentra ${ }^{\circledR}$, Puregene® (QIAGEN Group), 2007-2010.

https://www.qiagen.com/us/shop/sample-technologies/dna/genomic-dna/gentra-puregene-tissuekit/\#orderinginformation. Accessed 9 June 2017.

14. Sperling JL, Silva-Brandão KL, Brandão MM, Lloyd VK, Dang S, Davis CS, et al. Comparison of bacterial $16 \mathrm{~S}$ rRNA variable regions for microbiome surveys of ticks. Ticks Tick Borne Dis. 2017;8:453-61.

15. Caporaso JG, Lauber CL, Walters WA, Berg-Lyons D, Lozupone CA, Turnbaugh PJ, et al. Global patterns of $16 \mathrm{~S}$ rRNA diversity at a depth of millions of sequences per sample. Proceedings of the National Academy of Sciences. 2011;108(Supplement 1):4516-4522.

16. Edgar RC, Haas BJ, Clemente JC, Quince C, Knight R. UCHIME improves sensitivity and speed of chimera detection. Bioinformatics. 2011;27(16):2194-2200.

17. Glassing A, Dowd SE, Galandiuk S, Davis B, Jorden JR, Chiodini RJ. Changes in 16S RNA gene microbial community profiling by concentration of prokaryotic DNA. Journal of microbiological methods. 2015;119:239242.

18. Bokulich NA, Subramanian S, Faith JJ, Gevers D, Gordon JI, Knight R, Caporaso JG. Quality-filtering vastly improves diversity estimates from Illumina amplicon sequencing. Nature methods. 2013;10(1):57-59.

19. Andersen KS, Kirkegaard RH, Karst SM, Albertsen M. ampvis2: an R package to analyse and visualise 16S rRNA amplicon data. BioRxiv. 2018;299537. doi: https://doi.org/10.1101/299537

20. McMurdie PJ, Holmes S. phyloseq: an R package for reproducible interactive analysis and graphics of microbiome census data. PloS one. 2013;8(4):1-11

21. DeSantis TZ, Hugenholtz P, Larsen N, Rojas M, Brodie EL, Keller K, et al. Greengenes, a chimerachecked 16S rRNA gene database and workbench compatible with ARB. Applied and environmental microbiology. 2006;72(7):5069-5072.

22. Obregón D, Bard E, Abrial D, Estrada-Peña A, Cabezas-Cruz A. Sex-Specific Linkages Between Taxonomic and Functional Profiles of Tick Gut Microbiomes. Front. Cell. Infect. Microbiol. 2019;9:298. doi:10.3389/fcimb.2019.00298

23. Qiu Y, Nakao R, Ohnuma A, Kawamori F, Sugimoto C. Microbial population analysis of the salivary glands of ticks; a possible strategy for the surveillance of bacterial pathogens. PLoS One. 2014;9:e103961.

24. Van Treuren W, Ponnusamy L, Brinkerhoff RJ, Gonzalez A, Parobek CM, Juliano JJ, et al. Variation in the microbiota of Ixodes ticks with regard to geography, species, and sex. Appl Environ Microbiol. 2015;81:6200-9. 
25. Carpi G, Cagnacci F, Wittekindt NE, Zhao F, Qi J, Tomsho LP, et al. Metagenomic profile of the bacterial communities associated with Ixodes ricinus ticks. PLoS One. 2011;6:e25604.

26. Zhang X-C, Yang Z-N, Lu B, Ma X-F, Zhang C-X, H-J X. The composition and transmission of microbiome in hard tick, Ixodes persulcatus, during blood meal. Ticks Tick Borne Dis. 2014;5:864-70.

27. Menchaca AC, Visi DK, Strey OF, Teel PD, Kalinowski K, Allen MS, et al. Preliminary assessment of microbiome changes following blood-feeding and survivorship in the Amblyomma americanum nymph-to-adult transition using semiconductor sequencing. PLoS One. 2013;8:e67129.

28. Clayton KA, Gall CA, Mason KL, Scoles GA, Brayton KA. The characterization and manipulation of the bacterial microbiome of the Rocky Mountain wood tick, Dermacentor andersoni. Parasit Vectors. 2015;8:632.

29. Crump JA, Sjölund-Karlsson M, Gordon MA, Parry CM. Epidemiology, clinical presentation, laboratory diagnosis, antimicrobial resistance, and antimicrobial management of invasive Salmonella infections. Clin Microbiol Rev. 2015; doi:10.1128/CMR.00002-15.

30. Jesser KJ, Noble RT. Vibrio ecology in the Neuse River Estuary, North Carolina, characterized by nextgeneration amplicon sequencing of the gene encoding heat shock protein 60 (hsp60). Appl Environ Microbiol. 2018;84:e00333-18. doi:https://doi.org/10.1128/AEM.00333-18.

31. Payne SM, Mey AR, Wyckoff EE. Vibrio iron transport: evolutionary adaptation to life in multiple environments. Microbiol Mol Biol Rev. 2016;80:69-90. doi:10.1128/MMBR.00046-15.

32. Boyd EF, Carpenter MR, Chowdhury N, Cohen AL, Haines-Menges BL, Kalburge SS, et al. Post genomic analysis of the evolutionary history and innovations of the family Vibrionaceae. Microbiol Spectr. 2015;3(5):1-43. doi:10.1128/microbiolspec.VE-0009-2014.

33. Maj A, Dziewit L, Czarnecki J, Wlodarczyk M, Baj J, et al. Plasmids of Carotenoid-Producing Paracoccus spp. (Alphaproteobacteria) - Structure, Diversity and Evolution. PLoS ONE 2013;8(11):e80258. doi:10.1371/journal.pone.0080258.

34. Patro LPP, Rathinavelan T. Targeting the Sugary Armor of Klebsiella Species. Front. Cell. Infect. Microbiol. 2019;9:367. doi:10.3389/fcimb.2019.00367.

35. Folkesson A, Jelsbak L, Yang L, Johansen HK, Ciofu O, Hoiby N, Molin S. Adaptation of Pseudomonas aeruginosa to the cystic fibrosis airway: an evolutionary perspective. Nat Rev Microbiol. 2012;10:841-851. doi:https://doi.org/10.1038/nrmicro2907.

36. Wong JSJ, Seaward LM, Ho CP, Anderson TP, Lau EOC, Amodeo MR, et al. Corynebacterium accolensassociated pelvic osteomyelitis. J Clin Microbiol. 2010;48(2):654-5.

37. Gay NR, Fleming E, Oh J. Draft genome sequence of Cloacibacterium normanense NRS-1 isolated from municipal wastewater. Genome Announc. 2016;4(6):e01397-16. doi:10.1128/genomeA.0139716.

38. Kurilshikov A, Livanova NN, Fomenko NV, Tupikin AE, Rar VA, Kabilov MR, et al. Comparative metagenomic profiling of symbiotic bacterial communities associated with ixodes persulcatus, ixodes pavlovskyi and dermacentor reticulatus ticks. PLoS One. 2015;10(7):1-13.

39. Martínez MA. Retrato Microbiológico. J Microbiol Immunol Infect. 2011;44(1):289-95. 
40. Moreno-Forero SK, Van Der Meer JR. Genome-wide analysis of Sphingomonas wittichii RW1 behaviour during inoculation and growth in contaminated sand. ISME J. 2015;9(1):150-65.

41. Giron S. Diversidad bacteriana de la garrapata Rhipicephalus (Boophilus) microp/us en el ganado bovino del estado de Tamaulipas [Bacterial diversity of Rhipicephalus (Boophilus) microplus tick in cattle of the state of Tamaulipas]. 2015. [Thesis]. Thesis to obtain the title of Master of Science in Genomic Biotechnology viable in: https://tesis.ipn.mx/handle/123456789/24552. Accessed 14 October 2019.

42. Jimemez M, Gasper M, Carmona M, Terio K. Suidae and Tayassuidae. Pathology of Wildlife and Zoo Animals; 2018. p. 207-228

43. Sutherland-Smith M, Suidae and Tayassuidae (Wild Pigs, Peccaries). Fowler's Zoo and Wild Animal Medicine. 2015;(8):568-584

44. Bermúdez S, Meyer N, Moreno R, Artavia A. NOTAS SOBRE Pecari tajacu (L., Y Tayassu peccari (LINK, 1795) (ARTIODACTYLA: TAYASSUIDAE) COMO HOSPEDEROS DE GARRAPATAS DURAS (ACARI: IXODIDAE) EN PANAMÁ. Tecnociencia. 2008;20(1):61-70.

45. Rodríguez-Vivas RI, Quiñones AF, Fragoso SH. Epidemiología y control de la garrapata Boophilus en México [Epidemiology and control of Boophilus tick in Mexico]. In: Rodríguez-Vivas RI, editors. Enfermedades de importancia económica en producción animal [Diseases of economic importance in animal production]. México DF: McGraw-Hill-UADY; 2005. p. 571-592.

46. Duron O, Binetruy F, Noël V, Cremaschi J, McCoy KD, Arnathau A, et al. Evolutionary changes in symbiont community structure in ticks. Mol. Ecol. 2017;26:2905-2921. doi:10.1111/mec.14094.

47. Zhong J, Jasinskas A, Barbour AG. Antibiotic treatment of the tick vector Amblyomma americanum reduced reproductive fitness. PLoS ONE. 2007;2:e405. doi:10.1371/journal.pone.0000405.

48. Gottlieb Y, Lalzar I, Klasson L. Distinctive genome reduction rates revealed by genomic analyses of two Coxiella-like endosymbionts in ticks. Genome Biol. Evol. 2015;7:1779-1796. doi:10.1093/gbe/evv108.

49. Gerhart JG, Moses AS, Raghavan R. A Francisella-like endosymbiont in the Gulf Coast tick evolved from a mammalian pathogen. Sci. Rep. 2016;6:33670. doi:10.1038/srep33670.

50. Sjodin A, Svensson K, Ohrman C, Ahlinder J, Lindgren P, Duodu S, et al. Genome characterisation of the genus Francisella reveals insight into similar evolutionary paths in pathogens of mammals and fish. BMC Genomics. 2012;13:268. doi:10.1186/1471-2164-13-268.

\section{Figures}




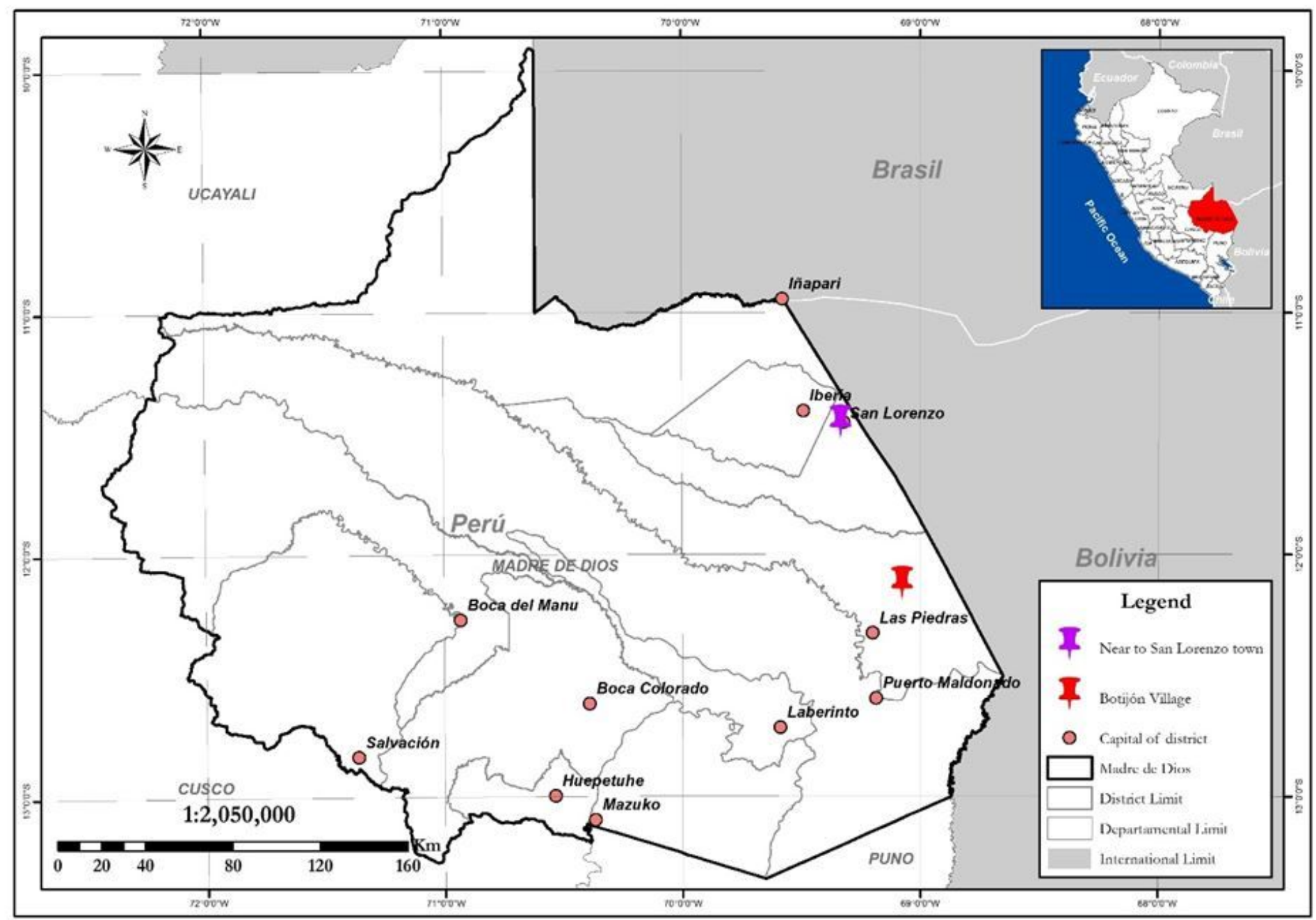

Figure 1

Botijón Village where samples were collected, and San Lorenzo town where cattle farming is practiced. 


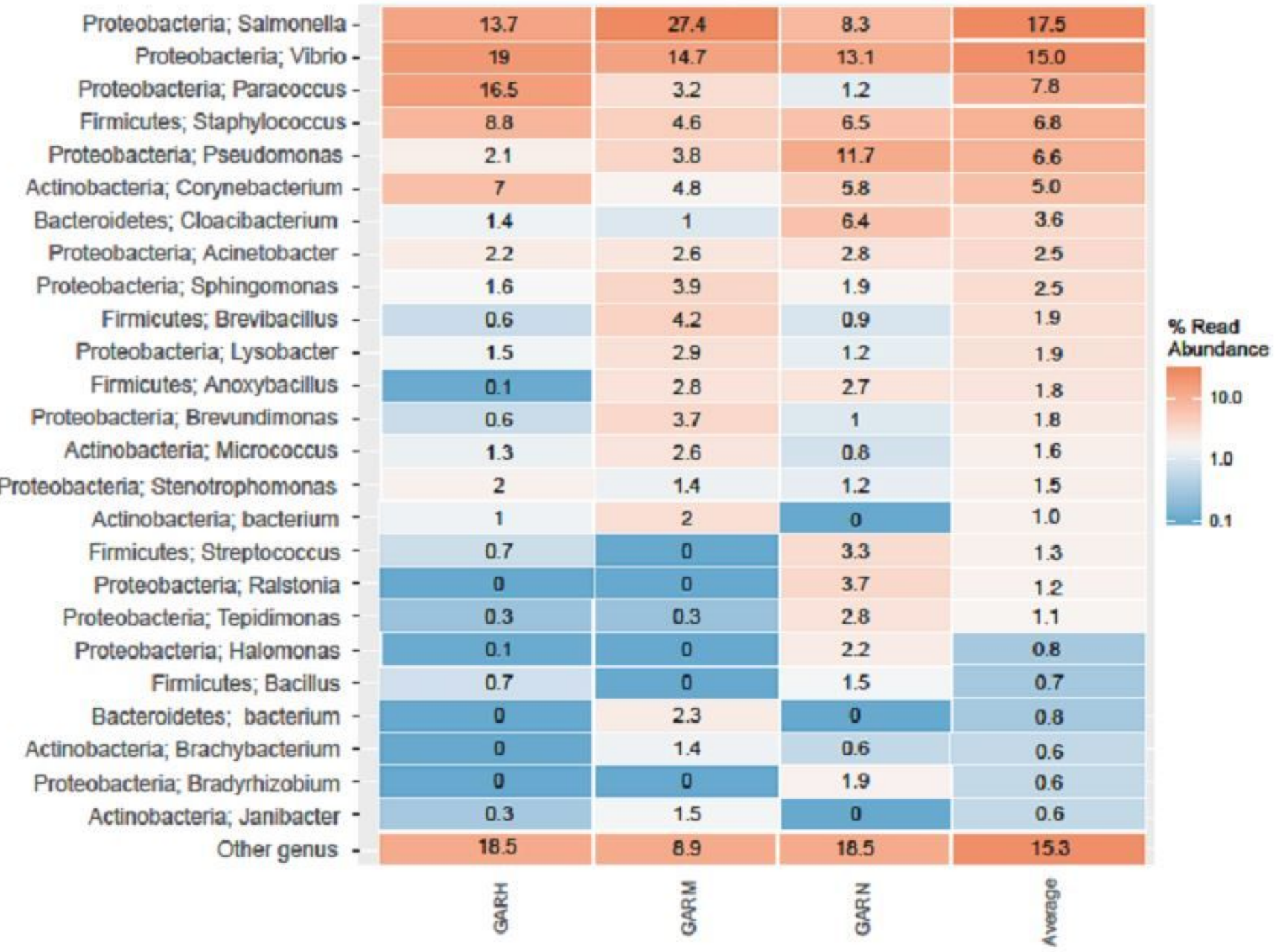

Figure 2

Microbiome abundance according to R. microplus stage and sex. 